\title{
Analysis of Chinese Rural Health Insurance System
}

\author{
Yan $\mathrm{Su}^{1, *}$ \\ ${ }^{1}$ Wenzhou Yuying International Experimental School, Wenzhou, Zhejiang 325014, China \\ *Corresponding author. Email:angela@cas-harbour.org
}

\begin{abstract}
This paper investigates the early origin of Chinese health insurance and factors of starting the appearance of NCMS (New Rural Cooperative Scheme). It also expects to find the problems of present NCMS and discusses the measures which can be taken to tackle them. Those main topics are concluded after obtaining information from publications and documents of policy. Among them, several main references based on database with a huge amount of information is emphasized. The paper identifies the lack of original rural health insurance in China, especially the period before the reform of China. In addition, two necessary factors that make the health insurance develop are concluded as the local setting of some experimental units and the maintenance of cooperative system. Moreover, problems like poor publicization, cumbersome procedures and information asymmetric are pointed out. Compared with the medical system in Canada, suggestions on narrowing the gap between the rich and the poor as well as the increasing types of illnesses that could be reimbursed are given. Generally speaking, the rural health insurance in past several decades have overcome lots of barriers but its future development is still waiting for proper adjustment.
\end{abstract}

Keywords: Rural China, Managerial economics, Health insurance, NCMS, Healthy economics

\section{INTRODUCTION}

The percentage of rural residents in China accounts for over $60 \%$ of the total population, which is a huge number. Although income of rural people keeps rising, it is still much lower than that of urban residents. It indicates that imbalanced urban-rural development is a prominent contradiction in China. Many rural residents with low earnings, especially people who engage in agriculture, confront the predicament of "Difficult to See a Doctor". Fortunately, from 2003, with the massive investment of tackling rural medical problem, the New Rural Cooperative Scheme (NCMS) has prevented them from illness-caused poverty. It is such a significant reform, which begs several main topics. For example, some parts of NCMS have been emphasized compared with the strategy before. What is more, the paper hopes to find existing problems and the part of system which is expected to be improved. The purpose of this passage is to give a new statement of a Chinese rural medical scheme and investigate its further development. This paper identifies the current situation of health insurance in the Chinese countryside, and attempts to compare the system in China with that in Canada. The author reviews the improvements of NCMS and then discusses the shortcomings of the present system as well as the suggestions to improve them.

\section{OVERVIEW OF PREVIOUS STUDIES}

This part offers at least three threads from which theory and insights might be woven. There are two researches on the development of Chinese medical schemes, two studies about the factors on how could NCMS appear, and three studies in the relationship between the improvement of schemes and real service, contributing to analyzing the Chinese insurance system. In a study which sets out to determine the development of health insurance in China, Liu (2004) shows the underlying reasons for the lack of the scheme in last century [3]. Surveys such as that conducted by Meng \& $\mathrm{Xu}$ (2014) [1] and Yuan \& Balabanova (2017) [6] have showed the main factors to start successful health insurance scheme. Respectively, Yip \& Hsiao (2009) [2] and Long (2010) [4] explores the existing problems and measures that can be taken. However, in general, prior work is still limited to the time and information. Furthermore, studies that explore improvement of scheme and the real service are usually about several cities, which is not a comprehensive overview. To conclude, the review of the literature revealed that all these studies provide important insights into health insurance and medical schemes yet they are generally much too old that some fresh changes in China should be added. 


\section{IMPROVEMENT OF NCMS}

\subsection{The Origin of Rural Cooperative Medical System}

In June 1965, China's people were notoriously unhealthy, with an average life expectancy of approximately 40 years at that time [5]. In order to make people's longevity longer and let people become healthier, the government implemented preventive strategies, emphasizing prevention sanitation as well as family planning. But without enough medical experts to help people solve their healthy problems, some individuals that live in communities are given minimal required training, who are known as "barefoot doctors" [3]. Although the program collapsed because of the economic reforms, it had successfully increased the Chinese life expectancy to 69 years old. However, without enough funding from the government, hospital focused more on profit-making, which causes the problem that rural residents could not afford the cost in the hospital.

\subsection{A New Beginning for Asking People to be Insured}

In 2003, a new communal medical insurance system was established to avoid the rural residents' inability to pay for treatments. It could be seen that the economy developed rapidly and vigorously, but the rural health insurance system did not make much great progress. Still, a large number of people remained uninsured. Fortunately, with the massive financial investment from governments and the accumulation of experiences, the rural health insurance scheme was gradually equipped with a solid theoretical and practical foundation. In 2004, rated people insured reached $72.6 \%$.

\subsection{Reasons for its Successful Appearance}

The financial investment is not the only factor that makes the scheme successfully develop. It is because many experimental units were gradually established in several cities [1]. And the experiences were summarized for adjusting the details of principles. In addition, from 200 yuan to 240 yuan in 2012 , then from 240 yuan to 280 yuan in 2013, the grants showed a considerable increasing as well. In the same year, the protection of major diseases began to include congenital heart disease, Leukemia, intestinal cancer, etc.

Eventually, the most significant property of NCMS is the cooperative system [6]. It means the rural insurance buyers will be insured fund that is raised by fees they paid (individual payment), collective support as well as public assistance. It enables rural residents to get more financial guidance when they are attacked by some serious diseases even though they could only pay an acceptable fee based on their disposable income.

\section{PROBLEMS OF NCMS}

\subsection{Publicity of the Scheme}

However, some existing problems are still negatively influenced by the further development of NCMS. Firstly, the publicity of the scheme is still emphasizing its superficial benefits instead of helping buyers to understand long-term advantages and foster an awareness of caring about their health risk. As those people are more likely to be lack of computing skills and the ability to access detailed information, they may feel that payment of insurance is bound to be a waste of money. Therefore, proper and effective publicity is more essential.

\subsection{Neglected Cumbersome Procedures}

Secondly, the cumbersome procedures should not be neglected. Usually, the registration is complex and the reimbursement procedures are also complicated. For rural residents who live far away from reimbursement centers, they may need to pay lots of extra fees for traffic in order to go through those formalities [2]. Then, if some people leave their hometown to work, the unfiled reimbursement standard will also make procedures more complex. Benefits of patients and their families are more likely to be negatively affected when conflict between different standards appears. Even worse, if they have some urgent diseases that need to be treated in general hospitals, they may fail to be reimbursed. Furthermore, from the perspective of supply side, the organizers of cooperative medical scheme also serve as managers, while there are no totally selfless regulators [7]. Their determinations usually tend to maximize the utility, which is likely to lead to the inefficiency in management and cause dissatisfaction among insurance holders.

\subsection{Imbalanced Condition}

It is known that medical insurance serves both social insurance and commercial insurance. The former is the fundamental protection and the latter is a supplement to it. For the rural residents who were buyers of insurance, the major challenges would be the "moral hazard" as well as "adverse selection", which are both caused by symmetrical information. The insurance buyer who knows that they are more likely to be attacked by some illnesses would participate in medical insurance. And the insured population usually costs more insurance fees than their uninsured counterparts because they are less likely to look after themselves than others who have to pay for health treatment without any reimbursement. In addition, those who are in unhealthy condition always fail to take commercial health insurance. At the same time, if treatments are recommended by doctor when patients are not with any pain, patients would always fail to know that the treatments are really in their best interests. For instance, some people may argue that it is the doctor that 
recommends the unnecessary treatment in order to gain extra payment; while the treatment is of great importance to their health.

As for the supplement of insurance, it is known that the system should satisfy diverse requirements of people from different religions. Government needs to suit the measures to local conditions, or residents in some lowincome regions with increasing demand for health protection but cannot be supported.

\section{DISCUSSION AND SUGGESTIONS}

To make a comparison for exploring the health insurance system in China, this paper takes the health insurance system in Canada as a comparing target. The health care system in Canada (which is also called Medicare) is one of the best health care system around the world. It is also a kind of free medical security, essentially using the funds from tax to support public hospitals. Partly, there are two factors regarding its success. The first one is that the gap between people with low income and people with high income is much narrower than any other country including the United States. To a large extent, it makes structure of social programs in Canada become tax-financed. The other factor is that life expectancy of Canadians is also much longer, and it still keeps rising which means that the healthy conditions of Canadians outperform many countries. It results from wide variation that is existing in different regions and social groups. Therefore, it shows the importance of narrowing the gap between the poor and the rich. But it does not mean China needs to construct a tax-based welfare system like Canada immediately, because it is necessary to take the condition of a whole country into consideration.

From another perspective, closing the gap and helping increase the income of rural residents can also motivate those residents to pay the fees instead of sacrificing the benefits to keep such a small amount of money.

When it comes to other aspects that can be improved, widening the range of protection, which means not only some serious diseases like cancers and rare diseases, but also some outpatient clinics, choric illnesses as well as some injury treatments should be included [4]. In this way, rural residents would have more enthusiasm to get to know the NCMS in advance. When their family numbers or themselves are attacked by those illnesses, the insurance will come in handy. After more and more people get benefits from it, it will undoubtedly become more and more popular, thus making the generalization of NCMS become more effective.

Another measure that should be taken is strengthening the construction of health and sanitation infrastructures in rural areas. After that, medical personnel can get sound training in particular hospitals or medical services institutes, preventing unprofessional cases during treatments. What is more, it can offer rural residents' opportunities to solve their health problems in county-level hospitals instead of being forced into general hospitals.

\section{CONCLUSION}

In conclusion, this paper concludes by arguing that the Chinese national medical cooperative scheme has experienced a lot of improvements. From a new particular scheme targeting at solving Chinese rural health problems, its predecessor confronted many obstacles and even collapsed. Fortunately, following the changes that happened in twentieth century China, the development of it showed considerable progress. Cooperative systems that deal with the difficulties of collecting funds and the setting of experimental units contribute to the spreading of rural health insurance scheme, as it was even called "the role model of health insurance" in developing countries. But several serious problems including complicated reimbursement, regional differences, poor publicity, drawbacks of asymmetric information still exist. Taking medicare in Canada as an example, the most important point that can be learned is to keep the balance of different income populations. Moreover, making the range of protection wider and the advancement of medical infrastructure constructions can also be beneficial. In the future, for enhancing the rural health insurance scheme, the improvements of regulation and more information which can be more transparent are needed. More papers that identify the current situation of health insurance in rural China, which are based on managerial economics or deep analysis of the accessibility of health insurance in other countries, may help us explore more specific measures that would be suitable for our country.

\section{ACKNOWLEDGMENTS}

I am deeply grateful to Pro. Lichtenberg's enlightening courses regarding Health courses which motivate me to write this paper. Also, I appreciate the unreserved guidance from my teaching assistants Kejia, Patrick and Jane. Without them would be impossible for me to compete this. I also would like to appreciate that all of my family members and friends for their helpful comments and encouragements.

\section{REFERENCES}

[1] Q. Meng, \& K. Xu, Progress and challenges of the rural cooperative medical scheme in China. Bulletin of the World Health Organization, 2014, 92, pp. 447451.

[2] W. Yip, \& W. C. Hsiao, Non-evidence-based policy: how effective is China's new cooperative medical scheme in reducing medical impoverishment?. 
Social science \& medicine, 2009, 68 (2), pp. 201209.

[3] Y. Liu, Development of the rural health insurance system in China. Health policy and planning, 2004, 19(3), pp.159-165.

[4] Q. Long, T. Zhang, L. Xu, S. Tang, \& E. Hemminki, Utilisation of maternal health care in western rural China under a new rural health insurance system (New Co-operative Medical System). Tropical Medicine \& International Health, 2010, 15(10), pp.1210-1217.

[5] World Bank. 1997, Financing health care: issues and options for China. Washington, DC: World Bank.

[6] B. Yuan, W. Jian, L. He, B. Wang, \& D. Balabanova, The role of health system governance in strengthening the rural health insurance system in China. International journal for equity in health, 2017, 16(1), p. 44.

[7] Y. Liu, \& K. Rao, Providing health insurance in rural China: from research to policy. Journal of health politics, policy and law, 2006, 31(1), pp. 71-92. 